\title{
Genetic Variations in Inflammatory Response Genes and Their Association with the Risk of Prostate Cancer
}

\author{
Xin Cui, Hao Yan, Tong-Wen Ou, Chun-Song Jia, Qi Wang, and Jian-Jun Xu \\ Department of Urology, Xuanwu Hospital, Capital Medical University, Beijing 100053, China \\ Correspondence should be addressed to Tong-Wen Ou; outongwen@sohu.com
}

Received 1 April 2015; Revised 25 May 2015; Accepted 10 June 2015

Academic Editor: Sabine Rohrmann

Copyright (C) 2015 Xin Cui et al. This is an open access article distributed under the Creative Commons Attribution License, which permits unrestricted use, distribution, and reproduction in any medium, provided the original work is properly cited.

Prostate cancer is a common cancer in men. Genetic variations in inflammatory response genes can potentially influence the risk of prostate cancer. We aimed to examine the association between PPARG Pro12Ala, NFKB1 -94 ins/del, NFKBIA -826C/T, COX-1 $(50 \mathrm{C}>\mathrm{T})$, and $C O X-2(-1195 \mathrm{G}>\mathrm{A})$ polymorphisms on prostate cancer risk. The genotypes of the polymorphisms were ascertained in 543 prostate cancer patients and 753 controls through PCR-RFLP and the risk association was evaluated statistically using logistic regression analysis. The NFKB1 -94 polymorphism was shown to decrease prostate cancer risk in both heterozygous and homozygous comparison models (odds ratios of $0.74(95 \% \mathrm{CI}=0.58-0.96)(P=0.02)$ and $0.57(95 \% \mathrm{CI}=0.42-0.78)(P<0.01)$, resp.). An opposite finding was observed for COX-2 (-1195) polymorphism (odds ratios of $1.58(95 \% \mathrm{CI}=1.15-2.18)(P<0.01)$ for heterozygous comparison model and $2.08(95 \% \mathrm{CI}=1.48-2.92)(P<0.01)$ for homozygous comparison model). No association was observed for other polymorphisms. In conclusion, NFKB1 -94 ins/del and COX-2 (-1195G>A) polymorphisms may be, respectively, associated with decreased and increased prostate cancer risk in the Chinese population.

\section{Introduction}

Prostate cancer is a form of cancer in which malignant cells develop in the prostate gland of the male reproductive system. Prostate cancer is the second leading type of cancer in men globally, with an age-standardized incidence rate of $31.1 \mathrm{per}$ 100,000 men [1]. In 2012 alone, a total of 1,111,689 cases of prostate cancers were diagnosed, and approximately 307,471 deaths were attended [1]. In comparison, the estimated numbers of incidence and mortality of the cancer were 679,000 and 221,000, respectively, in 2002 [2]. Thus, a marked increase in the incidence and mortality of prostate cancer has been observed during the past decade, and development of an effective screening strategy for identifying individuals at risk of prostate cancer is greatly needed. This is especially true for the Chinese population, in which the mortality-toincidence rate ratio (MR/IR) has been consistently higher in comparison to the average MR/IR of Asian countries and Western populations $[3,4]$.

Established etiological factors of prostate cancer include age, ethnicity, diet, and environmental carcinogen exposure [5]. The interactions among the above elements are believed to play significant roles in contributing to prostate carcinogenesis, although the precise mechanisms of this have not been fully understood [5]. In addition, in recent years, chronic inflammation of the prostate and, importantly, genetic profile of an individual have been shown to play an equally important role in oncogenesis of the prostate $[6,7]$. Epidemiological and molecular evidences implied that dysregulation of inflammatory response genes may promote the development and progression of approximately $20 \%$ of prostate malignancies by inducing DNA damage, cell proliferation enhancement, apoptosis inhibition, and angiogenesis simulation [8].

The most common cause of inflammatory response gene dysregulations is mutations in high penetrance genes [9]. Despite the fact that such mutations can strongly increase the risk of prostate cancer, they are only present in a small frequency in the general population [9]. In comparison, genetic variations in the form of single nucleotide polymorphisms (SNPs) in low penetrance genes can increase the risk of cancer modestly, but they are more prevalent in the general population and, thus, their overall impact could be substantial [10]. SNPs may alter the expression and functionality 
of the protein products [11], and many studies have showed a relationship between inherited variations in inflammatory response genes and the risk of prostate carcinogenesis [1216]. However, the influence of several common SNPs in the inflammatory response genes, either individually or in combinations, on prostate cancer risk has been understudied in the Chinese population. This includes the PPARG Pro12Ala polymorphism, NFKB1 -94 ins/del polymorphism, NFKBIA 826C/T polymorphism, COX-1 (50C $>\mathrm{T})$ polymorphism, and COX-2 (-1195G $>$ A) polymorphism. The present study aimed to investigate the association of the above polymorphisms with the risk of prostate cancer in the Chinese population.

\section{Materials and Methods}

2.1. Study Subjects. The study was approved by the Medical Ethics Committee of the Xuanwu Hospital, Beijing, China. All subjects were recruited from Xuanwu Hospital, Beijing, China, between October 2010 and August 2014. A total of 543 males who were diagnosed by qualified physicians as prostate cancer patients based on clinical, pathological, and laboratory tests were recruited into the study. To ensure consistency, only patients with high grade prostate cancer (Gleason score $>7$ ) who had a PSA level of $>10 \mathrm{ng} / \mathrm{mL}$ were included in the study. At the same period of time, a total of 753 healthy controls were enrolled into this study. Eligibility criteria for control included no individual history of cancer and no known genetic syndromes associated with prostate cancer and a PSA level of $<2 \mathrm{ng} / \mathrm{mL}$. Blood samples were collected from the subjects who meet the criteria mentioned above after obtaining written informed consent.

2.2. SNP Genotyping. Genomic DNA extraction was done by using EasyPure Blood Genomic DNA Kit (TransGen Biotech, Beijing, China) after the blood samples were taken from peripheral blood of all subjects. The DNA was used for genotyping of the five SNPs by using the PCR-RFLP method. All PCR were performed in a $25 \mu \mathrm{L}$ reaction mixture containing standard PCR buffer, $1.5 \mathrm{mM} \mathrm{MgCl}_{2}, 0.25 \mathrm{mM}$ $\mathrm{dNTP}, 1$ unit Taq polymerase, and $0.4 \mu \mathrm{M}$ of each primer. For all polymorphisms, approximately $10 \%$ of the samples were chosen at random and sequenced to confirm the genotypes from the amplified PCR product. The laboratory personnel performing the genotyping were blinded to the identity, the case-control status, and source of the samples.

2.2.1. PPARG Prol2Ala Polymorphism. The PCR primers used for amplification of the region containing the PPARG Pro12Ala polymorphism were $5^{\prime}$-GCC AAT TCA AGC CCA GTC-3' and $5^{\prime}$-GAT ATG TTT GCA GAC AGT GTA TCA GTG AAG GAA TCG CTT TCC-3'. The annealing temperature of the reaction was $58^{\circ} \mathrm{C}$. The PCR amplification produced a fragment of $270 \mathrm{bp}$ in size, which was then digested using BstUI restriction enzyme. The fragment was cleaved into a $227 \mathrm{bp}$ and a $43 \mathrm{bp}$ fragment for the Ala/Ala genotype while the Pro/Pro genotype was uncut. Apart from that, heterozygous genotype (Pro/Ala) was detected by the presence of all the above bands in agarose gel.
2.2.2. NFKB1-94 ins/del Polymorphism. The PCR for amplification of the region containing the NFKB1 -94 ins/del polymorphism was performed by using $5^{\prime}$-TGG GCA CAA GTC GTT TAT GA- $3^{\prime}$ and $5^{\prime}$-CTG GAG CCG GTA GGG AAG- $3^{\prime}$ primers, which were annealed to the genomic DNA at $61^{\circ} \mathrm{C}$. PflMI restriction enzyme was subsequently used to digest the amplified PCR product of $281 \mathrm{bp}$ in size. For ins/ins genotype, the absence of restriction site resulted in the undigested fragment of $281 \mathrm{bp}$ after the reaction. On the other hand, a $240 \mathrm{bp}$ and a $45 \mathrm{bp}$ fragment were obtained for the del/del genotype, while a $281 \mathrm{bp}$, a $240 \mathrm{bp}$, and a $45 \mathrm{bp}$ fragment were found in the ins/del genotype.

2.2.3. NFKBIA -826C/T Polymorphism. The NFKBIA $826 \mathrm{C} / \mathrm{T}$ polymorphism was genotyped by first amplifying the region of interest by using the following PCR primers: $5^{\prime}$ GGT CCT TAA GGT CCA ATC G-3' and $5^{\prime}$-GTT GTG GAT ACC TTG CAC TA- $3^{\prime}$ at an annealing temperature of $59.5^{\circ} \mathrm{C}$. This produced an amplicon of $200 \mathrm{bp}$ in size. Restriction enzyme digestion was performed with BfaI restriction enzyme. The TT genotype was uncut by the enzyme and remained $200 \mathrm{bp}$, but the CC genotype was cleaved into $180 \mathrm{bp}$ and $20 \mathrm{bp}$ bands. Heterozygotes showed all three bands on agarose gel.

2.2.4. COX-1 (50C>T) Polymorphism. The PCR primers used were $5^{\prime}$-GGT GCC CGG TGG GGA ATT TTC-3' and $5^{\prime}$ GAG GGG AAA GGA GGG GGT TG-3. The annealing temperature used was $60^{\circ} \mathrm{C}$. The PCR reaction generated a product of $245 \mathrm{bp}$. Then, the fragment was digested by using SmuI restriction enzyme. The TT genotype was not cut by the enzyme, hence remaining as a 245 bp band on agarose gels. The CC genotyped, on the other hand, was cleaved into two fragments of $120 \mathrm{bp}$ and $125 \mathrm{bp}$ in size. Heterozygotes showed the presence of all the above bands in agarose gel.

2.2.5. COX-2 (-1195G>A) Polymorphism. The PCR primers used for amplification of the region containing the $C O X$ $2(1195 \mathrm{G}>\mathrm{A})$ polymorphism were $5^{\prime}$-CCC TGA GCA CTA CCC ATG AT- $3^{\prime}$ and $5^{\prime}$-GCCTTCATAGGAGATACTGG- $3^{\prime}$. The annealing temperature of the reaction was $62^{\circ} \mathrm{C}$. The PCR amplification gave a product of $273 \mathrm{bp}$ in size, which was then digested using PvuII restriction enzyme. The AA genotype was undigested, while the PCR product was cleaved into a $220 \mathrm{bp}$ and a $53 \mathrm{bp}$ fragment for the GG genotype. Apart from that, heterozygous genotype (AG) was detected by the presence of all the above bands on the agarose gel.

2.3. Statistical Analysis. Statistical analyses were carried out using the SPSS software package 18.0 (SPSS Inc., Chicago, IL). Mean age for cases and controls was evaluated by using Student's $t$-test. On the other hand, chi square test ( $\chi^{2}$ test) was used to determine the significance difference in the smoking status and the distribution of genotypes of the cases and controls. Odds ratios (ORs) and the corresponding 95\% confidence intervals (CI) calculated by using logistic regression analysis were used to analyze the association between the polymorphic genotypes and prostate risk, based 
TABLE 1: Difference between cases and controls characteristics.

\begin{tabular}{lccc}
\hline Characteristics & Case $(n=543)$ & Control $(n=753)$ & $P$ \\
\hline Age & & & 0.29 \\
Mean \pm SD & $69.90 \pm 8.43$ & $69.38 \pm 8.76$ & \\
Range & $48-87$ & $46-85$ & \\
Smoking status & & & 0.52 \\
Ever smokers & 247 & 329 & \\
Never smokers & 296 & 424 & \\
\hline
\end{tabular}

on heterozygous and homozygous comparison models, with the wild type genotype served as the reference. Odds ratios (ORs) of $>1.00$ indicated a positive risk association and vice versa. Interaction between the polymorphisms and smoking status, as well as between polymorphisms in related genes (NFKB1 and NFKBIA; COX-2 and COX-1), was tested by using the same logistic regression model as above, by using SPSS software. $P$ values of $<0.05$ were significant. For analyses involving gene-gene and gene-environment interaction, Bonferroni correction was applied for multiple testing, in which case the statistical significance was assumed at $P<0.025$.

\section{Results}

3.1. General Characteristics. Table 1 shows the difference between cases and controls in terms of age and smoking status. The ages of cases ranged from 48 to 87 years, and those of controls ranged from 46 to 85 years. The mean age was $69.90 \pm 8.43$ for cases while the mean age was $69.38 \pm 8.76$ for controls. No significant difference was observed between the mean ages of both groups $(P=0.29)$. For both cases and controls, the frequency of never smokers was slightly higher than ever smokers. In cases, 247 (45.49\%) were ever smokers and 296 (54.51\%) were never smokers, while, in controls, 329 (43.69\%) were ever smokers and $424(56.31 \%)$ were never smokers. The difference in the distribution of ever and never smokers among cases and controls was not significant $(P=$ $0.52)$.

3.2. Distribution of Genotypes. The distribution of genotypes of the five polymorphisms in cases and controls is shown in Table 2. For the NFKB1 -94 ins/del polymorphism, the frequency of ins/ins, ins/del, and del/del genotypes was 198, 246, and 99 in cases and 212, 355, and 186 in controls. Significant difference was observed between cases and controls in the distribution of genotypes $\left(\chi^{2}=13.12, P<0.01\right)$.

Apart from that, another polymorphism which showed significant difference between cases and controls in the genotypic distribution was the COX-2 (-1195G $>$ A) polymorphism. Among the cases, 71, 269, and 203 subjects had GG, GA, and AA genotypes, respectively. On the other hand, the distribution of the genotypes among the controls was 158, 378, and 217, respectively $\left(\chi^{2}=18.34, P<0.01\right)$.

For the three other polymorphisms, no statistically significant difference was observed between cases and controls in the genotypic distribution $(P>0.05)$. For NFKBIA $826 \mathrm{C} / \mathrm{T}$ polymorphism, the distribution of the CC, CT, and
TABLE 2: Distribution of genotypes.

\begin{tabular}{lcccc}
\hline Genotype & $\begin{array}{c}\text { Case } \\
(n=543)\end{array}$ & $\begin{array}{c}\text { Control } \\
(n=753)\end{array}$ & $\chi^{2}$ & $P$ \\
\hline NFKB1 -94 Ins/del & & & 13.12 & $<0.01$ \\
Ins/Ins & 198 & 212 & & \\
Ins/Del & 246 & 355 & & \\
Del/Del & 99 & 186 & & \\
NFKBIA -826C/T & & & 0.51 & 0.77 \\
CC & 382 & 541 & & \\
CT & 152 & 198 & & \\
TT & 9 & 14 & & \\
COX-2 (-1195G>A) & & & 18.34 & $<0.01$ \\
GG & 71 & 158 & & \\
GA & 269 & 378 & & \\
AA & 203 & 217 & & \\
COX-1 (50C>T) & & & 4.05 & 0.13 \\
CC & 452 & 655 & & \\
CT & 83 & 92 & & \\
TT & 8 & 6 & & \\
PPARG Prol2Ala & & 676 & & \\
Pro/Pro & 483 & 67 & & \\
Pro/Ala & 57 & & & \\
Ala/Ala & 3 & & & \\
\hline
\end{tabular}

TT genotypes was 382, 152, and 9 in cases and 541, 198, and 14 in controls $\left(\chi^{2}=0.51, P=0.77\right)$. For COX-1 $(50 \mathrm{C}>\mathrm{T})$ polymorphism, the CC, CT, and TT genotypes were, respectively, present in 452,83 , and 8 cases as well as 655 , 92 , and 6 controls $\left(\chi^{2}=4.05, P=0.13\right)$. On the other hand, for PPARG Prol2Ala polymorphism, 483, 57, and 3 cases had Pro/Pro, Pro/Ala, and Ala/Ala genotypes, while the distribution of the same genotypes in controls was 676,73 , and 4 , respectively ( $\chi^{2}=0.23, P=0.89$ ).

For all polymorphisms, the genotype distribution did not deviate significantly from Hardy Weinberg equilibrium, both among cases and among controls $(P>0.05)$.

3.3. Risk Association: Overall. Table 3 shows the association between the five polymorphisms and prostate cancer risk in the population studied. For NFKB1 -94 ins/del polymorphism, a significantly decreased prostate cancer risk was observed in the heterozygous comparison model (ins/del versus ins/ins) and homozygous comparison model (del/del versus ins/ins). In heterozygous comparison model, the odds ratio was $0.74(95 \% \mathrm{CI}=0.58-0.96)$, with a $P$ value of 0.02 . On the other hand, in homozygous comparison model, the odds ratio was $0.57(95 \% \mathrm{CI}=0.42-0.78, P<0.01)$.

For COX-2 (-1195G $>$ A) polymorphism, a significantly increased prostate cancer risk was observed in the heterozygous comparison model (GA versus GG) and homozygous comparison model (AA versus GG). In heterozygous comparison model, the odds ratio was 1.58 (95\% CI $=1.15-2.18$ ), with a $P$ value of 0.01 . On the other hand, in homozygous 
TABLE 3: Association between polymorphisms and prostate cancer risk.

\begin{tabular}{|c|c|c|c|c|}
\hline Genotype & Case $(n=543)$ & Control $(n=753)$ & OR (95\% CI) & $P$ \\
\hline \multicolumn{5}{|c|}{ NFKB1 -94 ins/del } \\
\hline Ins/Ins & 198 & 212 & Ref. & - \\
\hline Ins/Del & 246 & 355 & $0.74(0.58$ to 0.96$)$ & 0.02 \\
\hline Del/Del & 99 & 186 & $0.57(0.42$ to 0.78$)$ & $<0.01$ \\
\hline \multicolumn{5}{|c|}{ NFKBIA $-826 \mathrm{C} / \mathrm{T}$} \\
\hline $\mathrm{CC}$ & 382 & 541 & Ref. & - \\
\hline $\mathrm{CT}$ & 152 & 198 & 1.09 (0.85 to 1.39$)$ & 0.51 \\
\hline $\mathrm{TT}$ & 9 & 14 & 0.91 (0.39 to 2.13$)$ & 0.83 \\
\hline \multicolumn{5}{|c|}{$C O X-2(-1195 \mathrm{G}>\mathrm{A})$} \\
\hline GG & 71 & 158 & Ref. & - \\
\hline GA & 269 & 378 & $1.58(1.15$ to 2.18$)$ & 0.01 \\
\hline AA & 203 & 217 & $2.08(1.48$ to 2.92$)$ & $<0.01$ \\
\hline \multicolumn{5}{|c|}{$C O X-1(50 \mathrm{C}>\mathrm{T})$} \\
\hline $\mathrm{CC}$ & 452 & 655 & Ref. & - \\
\hline CT & 83 & 92 & $1.31(0.95$ to 1.80$)$ & 0.10 \\
\hline $\mathrm{TT}$ & 8 & 6 & $1.93(0.67$ to 5.61$)$ & 0.23 \\
\hline \multicolumn{5}{|c|}{ PPARG Pro12Ala } \\
\hline Pro/pro & 483 & 676 & Ref. & - \\
\hline Pro/ala & 57 & 73 & 1.09 (0.76 to 1.58$)$ & 0.63 \\
\hline Ala/ala & 3 & 4 & $1.05(0.23$ to 4.71$)$ & 0.95 \\
\hline
\end{tabular}

comparison model, the odds ratio was 2.08 (95\% CI $=1.48-$ 2.92, $P<0.01)$.

For NFKBIA $-826 \mathrm{C} / \mathrm{T}$ polymorphism, statistically not significant risk association was observed. The heterozygous comparison model (CT versus CC) showed an odds ratio of 1.09 (95\% CI $=0.85-1.39)$ and a $P$ value of 0.51 . On contrary, the homozygous comparison model (TT versus CC) showed an odds ratio of $0.9104(95 \% \mathrm{Cl}=0.39-2.13)$ and a $P$ value of 0.83 .

Similarly, lack of significant association was observed for COX $-1(50 \mathrm{C}>\mathrm{T})$ polymorphism and PPARG Pro12Ala polymorphism. Both the polymorphisms showed positive odds ratio values for both heterozygous and homozygous comparison models. For COX-1 $(50 \mathrm{C}>\mathrm{T})$ polymorphism, the odds ratio obtained in the heterozygous comparison model was 1.31 (95\% CI $=0.95-1.80, P=0.10)$, while that in the homozygous comparison model was 1.93 (95\% CI $=0.67-$ 5.61, $P=0.23)$. On the other hand, for PPARG Prol2Ala polymorphism, the odds ratio was $1.09(95 \% \mathrm{CI}=0.76-1.58)$ in the heterozygous comparison model $(P=0.63)$ and 1.05 $(95 \% \mathrm{CI}=0.23-54.71)$ in the homozygous comparison model $(P=0.95)$.

3.4. Risk Association: Interaction of Polymorphisms with Smoking Status. The interaction between smoking status and the polymorphisms in modulating prostate cancer risk was also formally investigated, and the results are shown in Table 4. Significant interaction with smoking status was observed only for the COX-2 (-1195G $>$ A) polymorphism $(P<$ $0.01)$, in which a significant risk association was observed between the AA genotype and ever smokers ( $O R=1.76,95 \%$ $\mathrm{CI}=1.28-2.41, P<0.01)$.
3.5. Risk Association: Gene-Gene Interactions. The effect of interactions between polymorphisms in related genes (NFKB1 and NFKBIA; COX-2 and COX-1) on the risk of prostate cancer was also examined (Table 5). Both NFKB1 and NFKBIA combination and COX-2 and COX-1 combination showed statistically significant interactions $(P=0.03$ and $P=$ 0.02 , resp.). For the interactions between $C O X-2-1195 \mathrm{G}>\mathrm{A}$ and $C O X-1(50 \mathrm{C}>\mathrm{T})$ polymorphisms, interaction between COX-2 (-1195AA) * COX-1 (50CT) genotypes conferred a risk increment with $\mathrm{OR}=1.83(95 \% \mathrm{CI}=1.06-3.17, P=$ $0.03)$. However, this was deemed not statistically significant after application of Bonferroni correction, where $P<0.025$ was considered as significant. For the interactions between NFKB1 -94 ins/del and NFKBIA -826C/T polymorphisms, statistically significant prostate cancer risk association was not observed for any polymorphic combination investigated. No other genotypic interactions yielded a statistically significant association.

\section{Discussion}

In this study, we investigated and established the association of five inflammation-related genetic polymorphisms, namely, PPARG Pro12Ala, NFKB1 -94 ins/del, NFKBIA -826C/T, COX $-1(50 \mathrm{C}>\mathrm{T})$, and $C O X-2(-1195 \mathrm{G}>\mathrm{A})$ polymorphisms, with prostate cancer risk in a Chinese population. These polymorphisms have been widely investigated for their associations with other cancers or in other populations, but report is scarce or unavailable for prostate cancer in the Chinese population. This novelty of data represents one of the strengths of the present study. Additionally, our study involved a considerably large number of subjects, which 
TABLE 4: Gene-environment interaction between the polymorphisms and smoking status.

\begin{tabular}{|c|c|c|c|}
\hline Interaction & $P$ for interaction & OR $(95 \% \mathrm{CI})$ & $P$ \\
\hline NFKB1 $*$ smoking status & 0.31 & & \\
\hline NFKB1 -94 ins/ins $*$ nonsmokers & & Ref. & - \\
\hline NFKB1-94 ins/del * smokers & & $1.01(0.76-1.33)$ & 0.96 \\
\hline NFKB1 -94 del/del $*$ smokers & & $0.74(0.50-1.10)$ & 0.14 \\
\hline NFKBIA * smoking status & 0.71 & & \\
\hline NFKBIA -826CC * nonsmokers & & Ref. & - \\
\hline NFKBIA -826CT $*$ smokers & & $1.13(0.80-1.60)$ & 0.49 \\
\hline NFKBIA -826TT $*$ smokers & & $1.41(0.35-5.66)$ & 0.63 \\
\hline COX-2* smoking status & $<0.01$ & & \\
\hline COX-2 (-1195GG) * nonsmokers & & Ref. & - \\
\hline COX-2 (-1195GA) * smokers & & $1.29(0.98-1.69)$ & 0.07 \\
\hline COX-2 (-1195AA $) *$ smokers & & $1.76(1.28-2.41)$ & $<0.01$ \\
\hline COX-1 $*$ smoking status & 0.13 & & \\
\hline COX-1 (50CC) * nonsmokers & & Ref. & - \\
\hline COX-1 (50CT) * smokers & & $1.46(0.92-2.32)$ & 0.11 \\
\hline COX-1 $(50 \mathrm{TT}) *$ smokers & & $2.38(0.57-10.00)$ & 0.24 \\
\hline PPARG * smoking status & 0.23 & & \\
\hline PPARG Pro/Pro * nonsmokers & & Ref. & - \\
\hline PPARG Pro/Ala $*$ smokers & & $0.92(0.50-1.68)$ & 0.11 \\
\hline PPARG Ala/Ala $*$ smokers & & N/A & N/A \\
\hline
\end{tabular}

There were two factors involved (polymorphism and smoking status) in each testing; hence, significance is assumed at $P<0.025$ after application of Bonferroni correction.

TABLE 5: Combination of polymorphisms and prostate cancer risk.

\begin{tabular}{|c|c|c|c|}
\hline Interaction & $P$ for interaction & OR $(95 \% \mathrm{CI})$ & $P$ \\
\hline NFKB1 * NFKBIA polymorphisms & 0.03 & & \\
\hline NFKB1 -94 ins/ins * NFKBIA -826CC & & Ref. & - \\
\hline NFKB1 -94 ins/del $*$ NFKBIA $-826 \mathrm{CT}$ & & $0.99(0.71-1.38)$ & 0.94 \\
\hline NFKB1 -94 del/del * NFKBIA -826TT & & $3.16(0.81-12.28)$ & 0.10 \\
\hline NFKB1 -94 ins/del $*$ NFKBIA $-826 \mathrm{CT}$ & & $0.65(0.39-1.07)$ & 0.09 \\
\hline NFKB1 -94 del/del $* N F K B I A-826 \mathrm{TT}$ & & N/A & - \\
\hline COX-2 (-1195GG) * COX-1 (50CC) & 0.02 & Ref. & - \\
\hline COX-2 (-1195GA) $*$ COX-1 (50CT) & & $1.34(0.87-2.07)$ & 0.19 \\
\hline COX-2 (-1195AA) $* C O X-1(50 \mathrm{CT})$ & & $1.83(1.06-3.17)$ & 0.03 \\
\hline COX-2 (-1195GA) $*$ COX-1 (50TT) & & N/A & - \\
\hline COX-2 (-1195AA) $*$ COX-1 (50TT) & & $1.47(0.30-7.29)$ & 0.64 \\
\hline
\end{tabular}

There were two polymorphisms involved in each testing; hence, significance is assumed at $P<0.025$ after application of Bonferroni correction.

increases the reliability of the results obtained. Apart from that, our study analyzed the combined effect of polymorphisms in a similar pathway (i.e., NFKB1 and NFKBIA; COX-2 and $C O X-1)$, an approach which has been neglected in many previous reports.

PPARG gene encodes for peroxisome proliferatoractivated receptor- $\gamma$ (PPAR- $\gamma$ ), which is a ligand-activated transcription factor that is pleiotropic in nature. PPAR$\gamma$ is best known for its function in the regulation of adipogenesis and fatty acid metabolism, but it appears that the protein also plays a role in several carcinogenic processes, including apoptosis, cell cycle control, and, notably, inflammation [17]. The Pro12Ala polymorphism has been shown previously to affect the binding affinity of PPAR$\gamma$ towards its target molecules [18]. Therefore, we postulated that this polymorphism could influence the risk of prostate cancer. However, we observed a lack of association between the PPARG Pro12Ala polymorphism and prostate cancer risk in our population. We propose that this observation could be due to the fact that although different genotypes of the polymorphism have different binding affinity to its target molecules, the difference is subtle and does not influence the ability of PPAR- $\gamma$ in activating the transcription of its target molecules. Our result was in agreement with a study from Finland [19] and in partial agreement with another study from USA [20], which showed that the polymorphism was 
associated with an increased prostate cancer risk only among individuals with high body mass index.

On the other hand, NFKB1 and NFKBIA encode for $\mathrm{NF}-\kappa \mathrm{B} 1$ and its inhibitor, $\mathrm{I} \kappa \mathrm{B} \alpha$, respectively. Both $\mathrm{NF}-\kappa \mathrm{B} 1$ and $\mathrm{I} \kappa \mathrm{B} \alpha$ are part of the NF- $\kappa \mathrm{B}$ pathway, which plays an important role in inflammation and other carcinogenic processes. The -94 ins/del polymorphism of NFKB1 and $-826 \mathrm{C} / \mathrm{T}$ polymorphism of NFKBIA have been shown to affect the transcriptional activity of the respective genes, as the polymorphisms were located in the promoter region of the genes [10, 12]. We observed that the NFKB1 -94 ins/del polymorphism was associated with decreased risk of prostate cancer in both heterozygous and homozygous comparison models, suggesting that the variant del allele may be linked to a reduced inflammatory status among its carriers and, therefore, a reduced risk. This risk reduction was in agreement with an in vitro assay which showed that the del allele decreased the transcriptional activity of NFKB1, thereby truncating its role in promoting inflammation, which in turn led to the decreased prostate cancer risk [21]. Our finding was also in agreement with two other previous studies on prostate cancers, namely, Zhang et al. [22] in China and Kopp et al. [13] in Denmark. For NFKBIA -826C/T polymorphism, no significant association with prostate cancer risk was observed. Despite many previous studies reported on the association (or lack of association) between the NFKBIA polymorphism and risk of various cancers [10, 23-25], we believe that this is the first work which examined its association with prostate cancer risk.

Cyclooxygenases are enzymes which catalyze the conversion of arachidonic acid to prostaglandins, which promote and regulate the process of inflammation. There are two isoforms of cyclooxygenases, namely, the constitutively expressed cyclooxygenase- 1 and inducibly expressed cyclooxygenase-2, which are encoded by $C O X-1$ and $C O X-$ 2 genes, respectively. The COX-1 $(50 \mathrm{C}>\mathrm{T})$ polymorphism is located within the coding region of the gene and can potentially influence the functional importance of the enzyme produced [26]. On the other hand, the promoter COX$2(-1195 \mathrm{G}>\mathrm{A})$ polymorphism can alter the transcriptional activity of the gene [27]. Our result showed the absence of prostate cancer risk association for the COX-1 $(50 \mathrm{C}>\mathrm{T})$ polymorphism. This indicates that, despite its functional importance, the polymorphism is not sufficiently strong to result in significant risk alteration among its carriers. We also showed the presence of an association between COX-2 ($1195 \mathrm{G}>\mathrm{A}$ ) polymorphism and increased prostate cancer risk in both heterozygous and homozygous comparison models. This suggests that the variant A allele of the COX-2 polymorphism could contribute to an increased prostate cancer risk among its carriers. The observation that the A allele increases prostate cancer risk can be explained by the fact that the A allele creates a c-Myb transcription factor binding site in the gene, resulting in an increased transcription of COX-2 [27]. This in turn leads to the greater promotion of inflammation, which mediates the process of carcinogenesis. Our study is the first to evaluate the association between $C O X-1(50 \mathrm{C}>\mathrm{T})$ polymorphism and prostate cancer risk, whereas several previous reports were available for the association between
COX-2 (-1195G $>$ A) polymorphism and prostate cancer risk. Our study results were in agreement with Sugie et al. [28] in a Japanese population, but Wu et al. (Taiwan) [29], Cheng et al. (USA) [30], and Kopp et al. (Denmark) [13] showed the absence of risk association between COX-2 (-1195G>A) polymorphism and prostate cancer risk.

In summary, we have demonstrated the presence of a positive prostate cancer risk association for COX-2 ($1195 \mathrm{G}>\mathrm{A}$ ) polymorphism, a negative risk association for NFKB1 -94 ins/del polymorphism, and absence of association for PPARG Pro12Ala polymorphism, NFKBIA -826C/T polymorphism, and COX-1 (50C>T) polymorphism. There are several limitations in this study. First, although the overall sample size was large, the sample size became small when analysis was performed separately between smokers and nonsmokers and when the genotypes were combined. In addition, we only included five polymorphisms which were considered more well established based on our literature review. Therefore, a more extensive examination for a greater number of polymorphisms in a larger sample size is needed and recommended for future work for reconfirmation of our findings.

\section{Conflict of Interests}

The authors declare that they have no conflict of interests.

\section{Authors' Contribution}

Xin Cui and Hao Yan contributed equally to this work.

\section{References}

[1] J. Ferlay, I. Soerjomataram, M. Ervik et al., GLOBOCAN 2012 v1.0, Cancer Incidence and Mortality Worldwide: IARC CancerBase No. 11, International Agency for Research on Cancer, Lyon, France, 2013, http://globocan.iarc.fr.

[2] D. M. Parkin, F. Bray, J. Ferlay, and P. Pisani, "Global cancer statistics, 2002," Ca: A Cancer Journal for Clinicians, vol. 55, no. 2, pp. 74-108, 2005.

[3] L. Zhang, S. Wu, L.-R. Guo, and X.-J. Zhao, "Diagnostic strategies and the incidence of prostate cancer: reasons for the low reported incidence of prostate cancer in China," Asian Journal of Andrology, vol. 11, no. 1, pp. 9-13, 2009.

[4] P. D. Baade, D. R. Youlden, S. M. Cramb, J. Dunn, and R. A. Gardiner, "Epidemiology of prostate cancer in the Asia-Pacific region," Prostate International, vol. 1, no. 2, pp. 47-58, 2013.

[5] M. F. Leitzmann and S. Rohrmann, "Risk factors for the onset of prostatic cancer: age, location, and behavioral correlates," Clinical Epidemiology, vol. 4, no. 1, pp. 1-11, 2012.

[6] O. N. Kryvenko, M. Jankowski, D. A. Chitale et al., "Inflammation and preneoplastic lesions in benign prostate as risk factors for prostate cancer," Modern Pathology, vol. 25, no. 7, pp. 10231032, 2012.

[7] M. M. Shen and C. Abate-Shen, "Molecular genetics of prostate cancer: new prospects for old challenges," Genes and Development, vol. 24, no. 18, pp. 1967-2000, 2010.

[8] A. M. De Marzo, E. A. Platz, S. Sutcliffe et al., "Inflammation in prostate carcinogenesis," Nature Reviews Cancer, vol. 7, no. 4, pp. 256-269, 2007. 
[9] M. J. Alvarez-Cubero, M. Saiz, L. J. Martinez-Gonzalez, J. C. Alvarez, J. A. Lorente, and J. M. Cozar, "Genetic analysis of the principal genes related to prostate cancer: a review," Urologic Oncology: Seminars and Original Investigations, vol. 31, no. 8, pp. 1419-1429, 2013.

[10] S. C. Tan, M. S. M. Suzairi, A. A. A. Aizat et al., "Gender-specific association of NFKBIA promoter polymorphisms with the risk of sporadic colorectal cancer," Medical Oncology, vol. 30, no. 4, article 693, 2013.

[11] X. Li, S.-J. Wang, S. C. Tan et al., "The A55T and K153R polymorphisms of MSTN gene are associated with the strength training-induced muscle hypertrophy among Han Chinese men," Journal of Sports Sciences, vol. 32, no. 9, pp. 883-891, 2014.

[12] M. S. Mohd Suzairi, S. C. Tan, A. A. Ahmad Aizat et al., "The functional -94 insertion/deletion ATTG polymorphism in the promoter region of NFKB1 gene increases the risk of sporadic colorectal cancer," Cancer Epidemiology, vol. 37, no. 5, pp. 634638, 2013.

[13] T. I. Kopp, S. Friis, J. Christensen, A. Tjønneland, and U. Vogel, "Polymorphisms in genes related to inflammation, NSAID use, and the risk of prostate cancer among Danish men," Cancer Genetics, vol. 206, no. 7-8, pp. 266-278, 2013.

[14] R. Kazma, J. A. Mefford, I. Cheng et al., "Association of the innate immunity and inflammation pathway with advanced prostate cancer risk," PLoS ONE, vol. 7, no. 12, Article ID e51680, 2012.

[15] M. Ianni, E. Porcellini, I. Carbone et al., "Genetic factors regulating inflammation and DNA methylation associated with prostate cancer," Prostate Cancer and Prostatic Diseases, vol. 16, no. 1, pp. 56-60, 2013.

[16] E. M. Kwon, C. A. Salinas, S. Kolb et al., "Genetic polymorphisms in inflammation pathway genes and prostate cancer risk," Cancer Epidemiology, Biomarkers \& Prevention, vol. 20, no. 5, pp. 923-933, 2011.

[17] H. Martin, "Role of PPAR-gamma in inflammation. Prospects for therapeutic intervention by food components," Mutation Research, vol. 690, no. 1-2, pp. 57-63, 2010.

[18] S. S. Deeb, L. Fajas, M. Nemoto et al., "A Pro12Ala substitution in PPARgamma2 associated with decreased receptor activity, lower body mass index and improved insulin sensitivity," Nature Genetics, vol. 20, no. 3, pp. 284-287, 1998.

[19] D. Paltoo, K. Woodson, P. Taylor, D. Albanes, J. Virtamo, and J. Tangrea, "Pro12Ala polymorphism in the peroxisome proliferator-activated receptor-gamma (PPAR-gamma) gene and risk of prostate cancer among men in a large cancer prevention study," Cancer Letters, vol. 191, no. 1, pp. 67-74, 2003.

[20] J. M. Zmuda, F. Modugno, J. L. Weissfeld et al., "Peroxisome proliferator-activated receptor- $\gamma$ polymorphism, body mass and prostate cancer risk: evidence for gene-environment interaction," Oncology, vol. 70, no. 3, pp. 185-189, 2006.

[21] A. S. Karban, T. Okazaki, C. I. M. Panhuysen et al., "Functional annotation of a novel NFKB1 promoter polymorphism that increases risk for ulcerative colitis," Human Molecular Genetics, vol. 13, no. 1, pp. 35-45, 2004.

[22] P. Zhang, Q. Wei, X. Li et al., "A functional insertion/deletion polymorphism in the promoter region of the NFKB1 gene increases susceptibility for prostate cancer," Cancer Genetics and Cytogenetics, vol. 191, no. 2, pp. 73-77, 2009.

[23] C.-W. Cheng, J.-L. Su, C.-W. Lin et al., "Effects of NFKB1 and NFKBIA gene polymorphisms on hepatocellular carcinoma susceptibility and clinicopathological features," PLOS ONE, vol. 8, no. 2, Article ID e56130, 2013.
[24] C.-W. Lin, Y.-S. Hsieh, C.-H. Hsin et al., "Effects of NFKB1 and NFKBIA gene polymorphisms on susceptibility to environmental factors and the clinicopathologic development of oral cancer," PLoS ONE, vol. 7, no. 4, Article ID e35078, 2012.

[25] M. Umar, R. Upadhyay, S. Kumar, U. C. Ghoshal, and B. Mittal, "Association of common polymorphisms in TNFA, NFkB1 and NFKBIA with risk and prognosis of esophageal squamous cell carcinoma," PLoS ONE, vol. 8, no. 12, Article ID e81999, 2013.

[26] J. Shi, N. L. A. Misso, D. L. Duffy et al., "Cyclooxygenase-1 gene polymorphisms in patients with different asthma phenotypes and atopy," European Respiratory Journal, vol. 26, no. 2, pp. 249256, 2005.

[27] H. S. de Vries, R. H. M. te Morsche, M. G. H. van Oijen, I. D. Nagtegaal, W. H. M. Peters, and D. J. de Jong, "The functional $-765 G \rightarrow C$ polymorphism of the COX-2 gene may reduce the risk of developing crohn's disease," PLoS ONE, vol. 5, no. 11, Article ID e15011, 2010.

[28] S. Sugie, H. Tsukino, S. Mukai et al., "Cyclooxygenase 2 genotypes influence prostate cancer susceptibility in Japanese Men," Tumor Biology, vol. 35, no. 3, pp. 2717-2721, 2014.

[29] H.-C. Wu, C.-H. Chang, H.-L. Ke et al., "Association of cyclooxygenase 2 polymorphic genotypes with prostate cancer in Taiwan," Anticancer Research, vol. 31, no. 1, pp. 221-225, 2011.

[30] I. Cheng, X. Liu, S. J. Plummer, L. M. Krumroy, G. Casey, and J. S. Witte, "COX2 genetic variation, NSAIDs, and advanced prostate cancer risk," British Journal of Cancer, vol. 97, no. 4, pp. 557-561, 2007. 


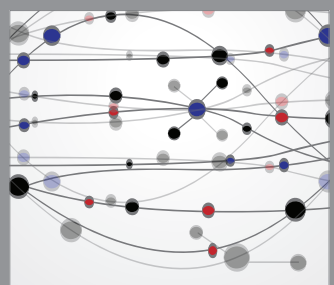

The Scientific World Journal
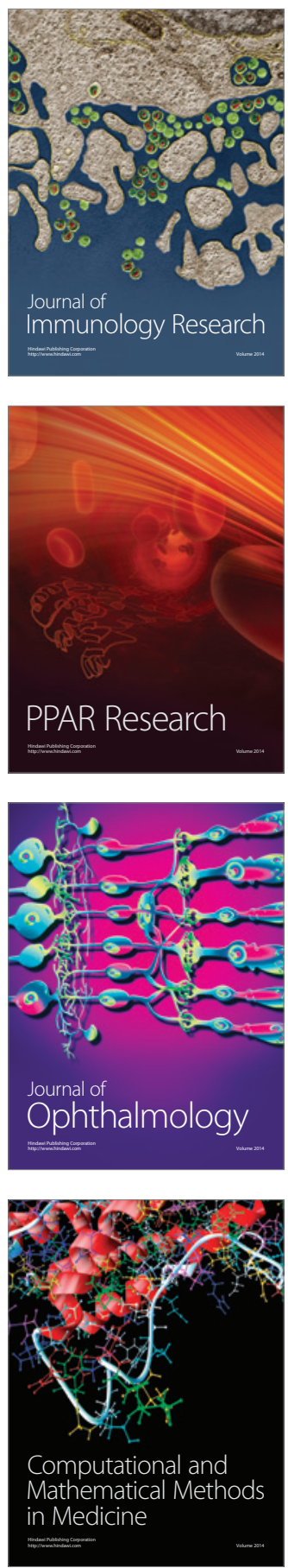

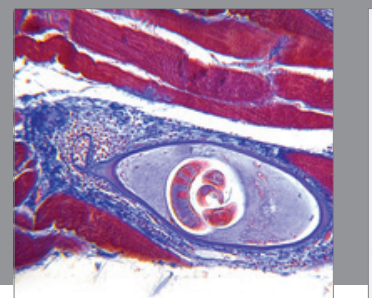

Gastroenterology

Research and Practice
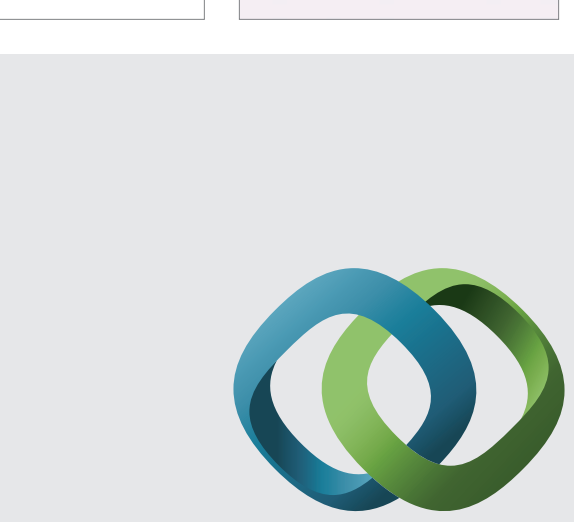

\section{Hindawi}

Submit your manuscripts at

http://www.hindawi.com
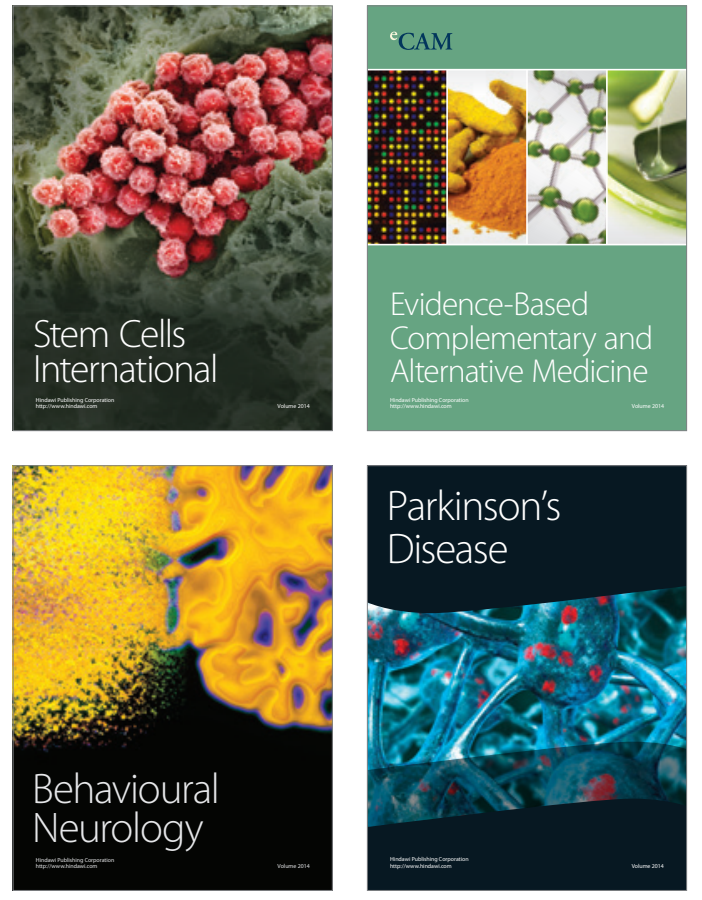
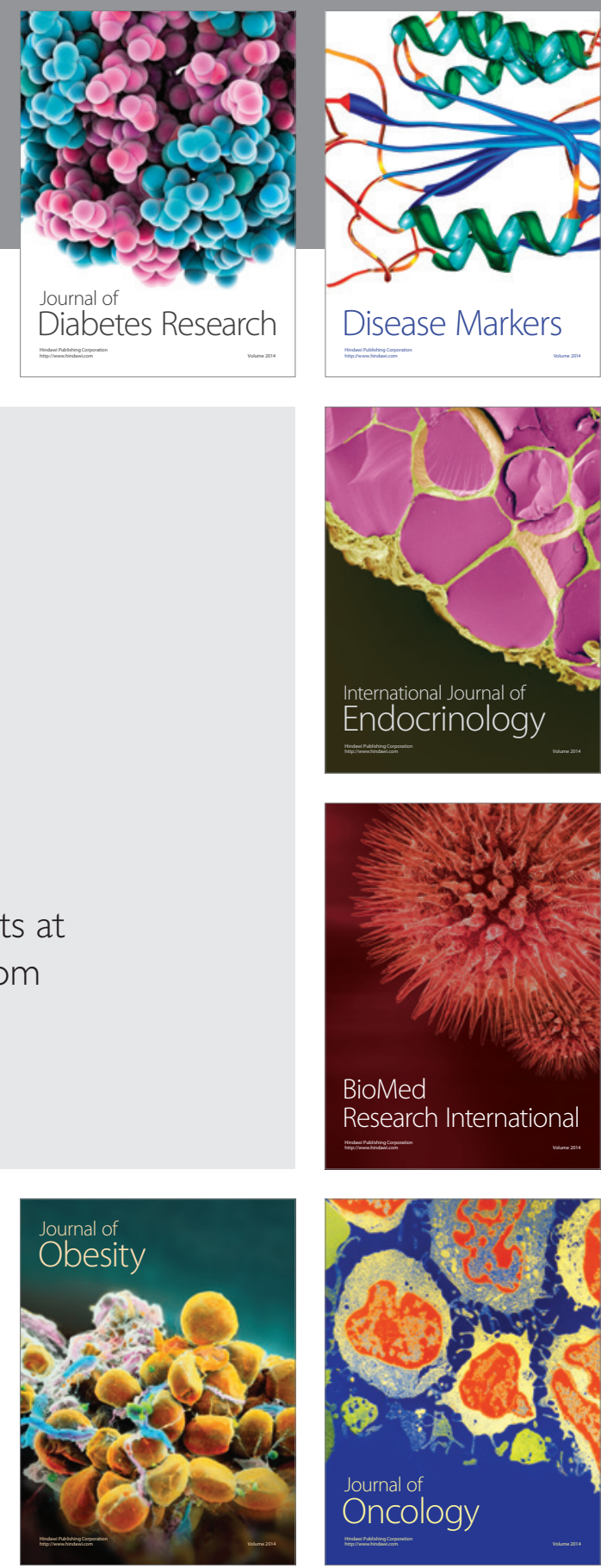

Disease Markers
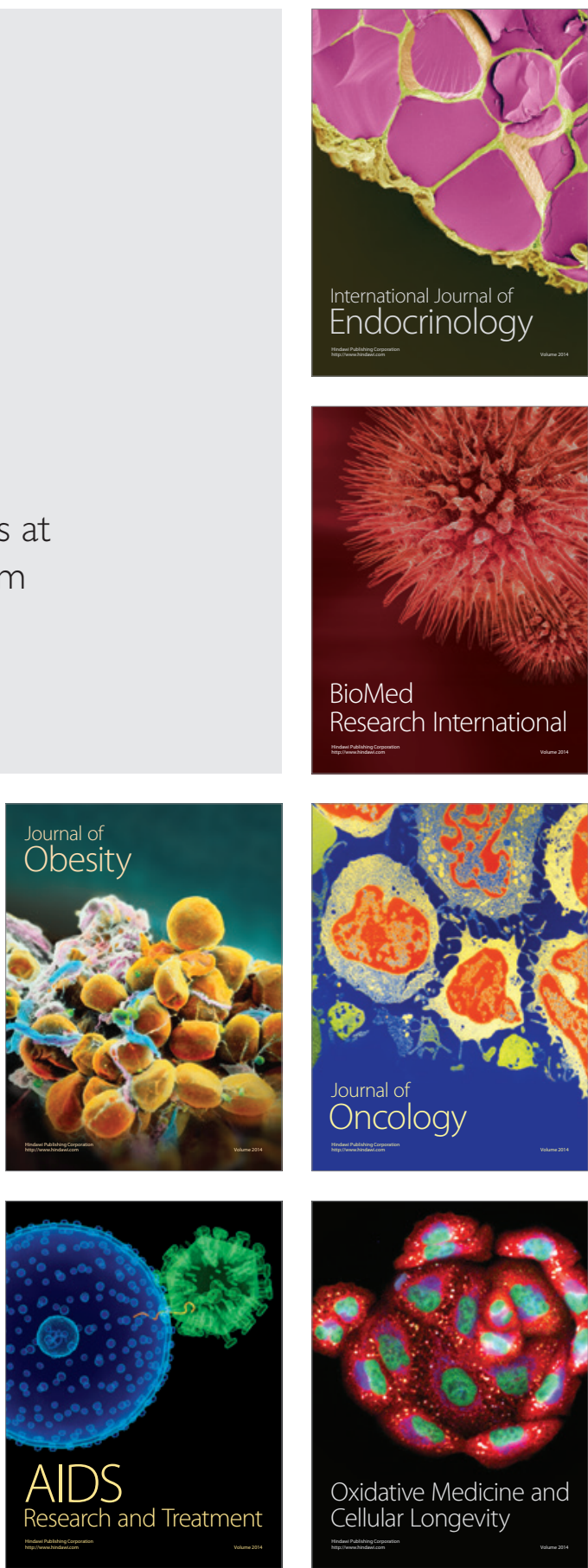